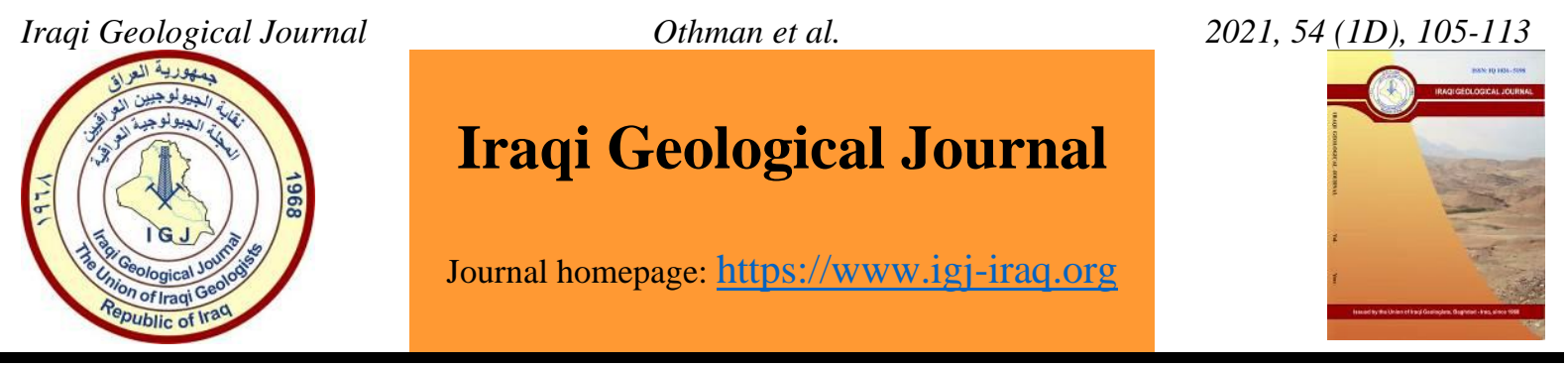

\title{
Predicting Tbm Performance for Pila Spi Formation in Qara Dagh Anticline, NE Iraq
}

\author{
Burkan S. Othman ${ }^{1, x}$, Ibtihal H. Salim ${ }^{2}$ and Muhammad N. Nuri ${ }^{3}$ \\ ${ }^{1}$ Department of Applied Geology, College of Science, University of Kirkuk, Kirkuk, Iraq \\ ${ }^{2}$ Department of Civil Engineering, College of Engineering, University of Samarra, Iraq \\ ${ }^{3}$ Department of Geology, Field Authority, Iraqi North Oil Company, Kirkuk, Iraq \\ ${ }^{\times}$Correspondence: selimburkan2015@gmail.com
}

Received:12 November 2020; Accepted: 11 February 2021; Published : 30 April 2021

\begin{abstract}
There are a few studies on the engineering properties of the Pila Spi Formations in scattered areas of Northern Iraq, but there is no study on predicting the performance of Tunnel Boring Machines (TBM), which is of great importance in future large engineering projects in Iraq. The study area is located on the Takya about $50 \mathrm{~km}$ south the center of Sulaimania City. Field and laboratory studies were conducted on five (5) selected sites situated in the southwestern flank of the Qara Dagh anticline. The axis of the anticline extends from NW-SE of Iraq with a length of roughly $116 \mathrm{~km}$. The engineering and field results of the samples collected from different locations indicate that the compressive strength of the rocks having a fine texture and slightly weathered characteristics ranges between strong to very strong with high dry density and low moisture content. In addition, the average Schmidt hammer rebound and weight losses percentages of Lose Angeles values are 48 and 22\%, respectively the sizes of the blocks range from large to very large, the spacing of the discontinuities is medium to wide. The performance of TBM in terms rate of advance is generally determined based on these geological rock materials and masses. To estimate the rate advance of boring machine (TBM) in this study, the method depends on the total hardness. After applying the total hardness method, it was estimated that the predicted rate of advancement of the TBM would be very slow (approximately $1.57-1.86 \mathrm{~m} / \mathrm{hr}$ ) due to the strong hardness of the rocks of Pila Spi Formation.
\end{abstract}

Keywords: TBM; Limestone; Pila Spi Formation; Qara Dagh anticline; Total hardness

\section{Introduction}

There are many engineering projects set up on rock masses such as dams, external roads, quarries and others, but engineers and entrepreneurs face some problems such as rock cutting, drilling and blasting when dealing with rocks. Rock drilling techniques, including drilling methods for deep foundations, blasting, road header tunneling machines, as well as Tunnel Boring Machines (TBM). TBM was first discovered by an American company in 1950 that has since dug hundreds of tunnels. As stated by Hansen et al. (2018), TBM technology has advanced considerably with a number of significant developments (Fig. 1). Up to now, several studies (Bieniawski and Galera, 2007; Barton, 2000; Howarth et al.,1986; Hassanpour et al., 2011; Tarkoy, 1973; Saffet and Halil 2015; Salimi et al., 2017; Maleki, 2018 and Lee et al., 2011) have been conducted on predicting the performance of the TBM in different statistical ways, depending on engineering coefficients and in different areas of the system. (Saffet et al., 2008) specified that many factors such as resistance, hardness, device design, RQD, DOI: 10.46717/igj.54.1D.9Ms-2021-04-29 
interruptions in rocks, brittleness, and toughness affect the performance of TBM. It was concluded from previous studies that there has never been researched in Iraq on the study of factors affecting the performance of drilling machines in rocks for engineering purposes such as tunnels, quarries or others, except some local studies on the engineering properties of Pila Spi Formation rocks in different areas of the Kurdistan region (Dhaher, 2009; Saleh, 2012; Omer and Ismail, 2015). All of these studies examined the mechanical and physical properties of rocks for their suitability as building materials. The study area consists of the presence of rock masses belonging to the composition of Pila Spi Formation, which is spoiled limestone and chalky limestone rocks, and the area is part of the Qara Dagh anticline, which extends from the northwest to the southeast of Iraq and the Pila Spi Formation represented as a high barrier resistant to erosion. The current study aims to estimate the physical and mechanical properties of the rocks and then predict the performance of the TBM based on the values of total hardness rock masses, for this purpose, five locations of hard chalky to dolomitic limestone rocks were selected from the study area. The mechanical and physical tests performed on the selected samples were point load Schmidt hammer and density tests. In addition, field measurements were taken for discontinuity in the selected locations represented by the spacing, the size of the rock masses and the wetness rate on the discontinuity planes of the rock masses.

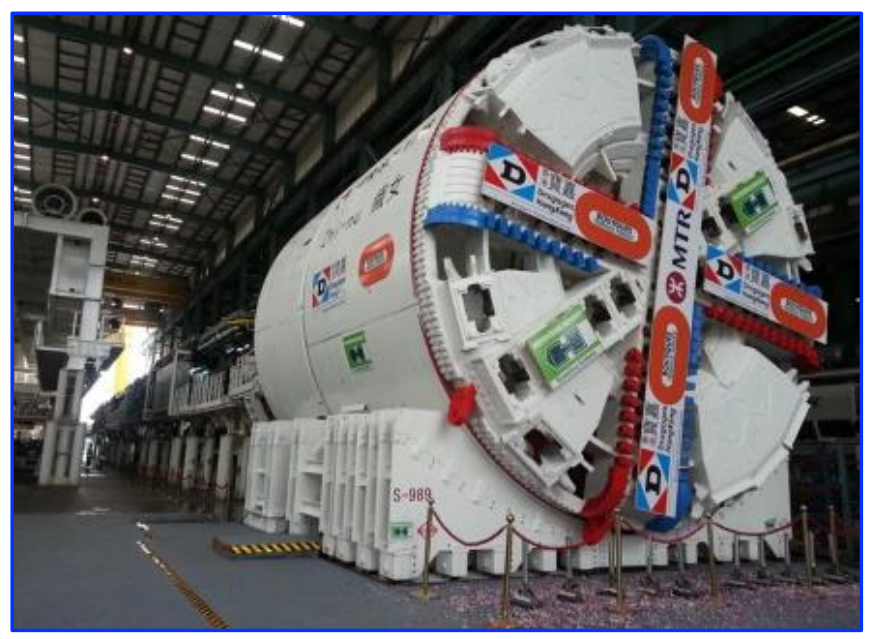

Fig.1. Tunneling Boring Machine (TBM)

\section{Geological Setting of The Study Area}

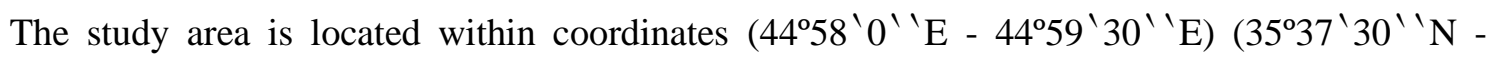
$35^{\circ} 39^{\prime} 0^{\prime} \mathrm{N}$ ) (about $50 \mathrm{~km}$ ) south of the center of Sulaimaniya city in northeastern Iraq. The study is part of the high fold zone of the unstable pavement of the Arab Shield. The research models were taken from the Pila Spi Formation which is outcropped on the southwest limb of the Qara Dagh anticline, their axis extension (SE-NW) and have about length of $116 \mathrm{~km}$ (Sissakian et al., 2018) (Fig. 2). The Pila Spi Formation forms most of the southwest limb (SW) of the Qara Dagh anticline and is covered in the limbs by formations Fatha, Injana, Muqdadiya and Bai Hasan. The formation settled in the shallow lagoon and dates to the Mid to Late Eocene (Jassim and Goff, 2006). The area is a high barrier (ridge) resulting from differential erosion between the crystallized Pila Spi limestone Formation (resistant to erosion) and weak, anti-stripping surrounding formations such as the Gercus and Kolosh formations (Huggett 2007). Limestone rocks in the study area are chalky sometimes dolomitic limestone rocks, yellowish to white grey color with soft granules with good bedded, partial stripping with a small amount of water on the surface of the discontinuity that may affect rock resistance (Jassim and Goff, 2006). 


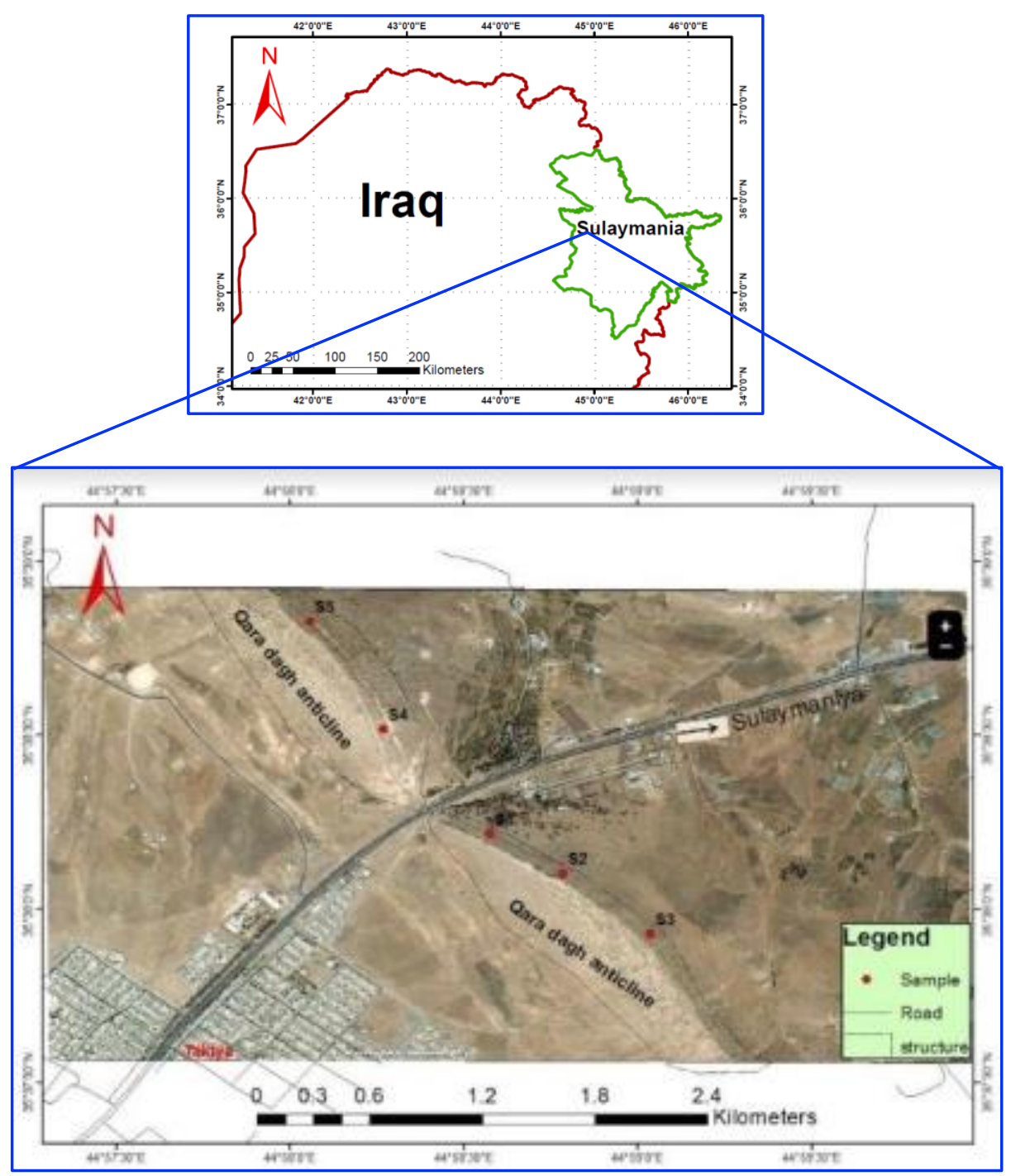

Fig. 2. Satellite image showing study area and locations of samples

\section{Materials and Methodology}

Five locations were identified from the study area with the coordinates of each location determined by a GPS device (Fig. 2). The rocks of the study area were described depending on their color, degree of bedding, humidity on the surfaces of the discontinuities, hardness, and degree of erosion. The descriptions done according to the NZ Geotechnical Society INC (2005). The tools used for the field descriptions and sampling included GPS for location coordinates, a camera, a geological hammer for sampling and determination of the hardness of rocks, a metric tape for measuring the dimensions of layers, and bags for transporting samples. One to two rock blocks were collected from each site and transported to the laboratory for laboratory tests of density, and wet percentage, while mechanical properties tested with point load strength test for compression strength and the abrasion rock test (Los Angeles test). Each test is described in more detail below. After obtaining laboratory and field results, the existing parameters are compared and discussed. Predicting the performance of the TBM was done using the procedure proposed by (Tarkoy, 1973). This method uses the relationship between the total hardness values resulting from the root relationship between the hardness of the hammer Schmit test and the abrasion hardness. The following is a brief description of the field and laboratory experiments conducted in this study. 


\subsection{Point Load Test}

The point load test is a common index test used by engineers both in the field and in the laboratory (Fig. 3). This test was first proposed by Broch and Franklin (1972). It measures the point load index value of rocks for indirectly estimating the uniaxial compressive and tensile strengths. The test was carried on the samples according to the method recommended by (ISRM, 1985) where 5-3 pieces of irregular sizes approximately $(50 \mathrm{~mm})$ were taken from each site and the sample is confined between the two conical contact points until the failure of the sample (10-60sec.) and the value $\left(I s_{50}\right)$ was obtained using Equation (1) below (This examination was conducted in the lab. of science college university of Kirkuk).

$$
I_{S}=\left[\frac{P}{D^{2}}\right] \times 100
$$

Where:

$\mathrm{I}_{\mathrm{s}}=$ point load strength index (Map)

$\mathrm{p}=\operatorname{load}(\mathrm{kN})$

$\mathrm{D}^{2}=$ for irregular samples $=4 \mathrm{~A} / \pi\left(\mathrm{mm}^{2}\right)$

$\mathrm{A}=\mathrm{WD} \mathrm{mm}^{2} \quad$ (minimum cross section area of a plane through the platen contact points)

W: width (mm)

D: distance between 2 conic contact points (mm)

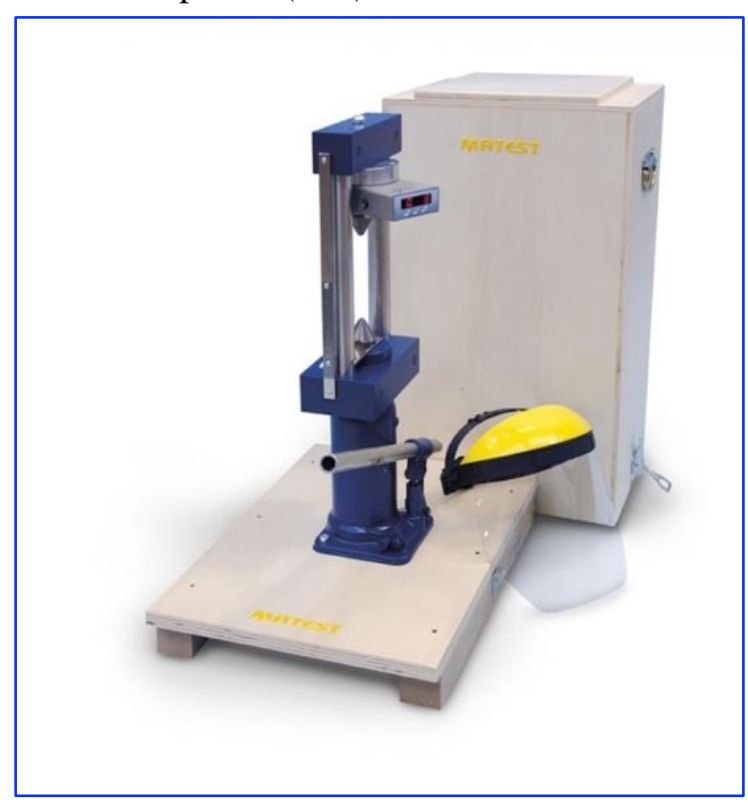

Fig. 3. Digital point load tester

\subsection{Schmidt Hammer Test}

The L-type Schmidt hammer test used to measure the hardness of rock and concrete surfaces and is useless in the case of very strong and very weak rocks. This test was carried out according to (ISRM, 1978), the hammer has been applied in the field on the clean, flat, crack-free, dry and vertical surfaces the average of 10 readings taking from each surface.

\subsection{Abrasion}

This method used to check aggregate resistance against scratching using Los Angeles device. The idea of the experiment is to find the difference between the weight of the initial total and the final weight after the rotation of the samples with the steel pieces inside the cylinder and express the weight lost by 
a percentage ISRM (1978). This test was conducted at the road Laboratory, Department of Civil Engineering, Kirkuk University. The mechanical scratch value is calculated by Equation (2) as below:

$$
\mathrm{AB} \frac{\mathrm{A}-\mathrm{B}}{\mathrm{A}} * 100 \ldots
$$

AB: Abrasion percentage

A: Total dry sample weight before examinatio (gm)

B: Remaining dry weight sample after examinatio (gm)

In order to predict the advance rate of the TBM for the rocks in the study area; firstly we obtain the total hardness $\left(\mathrm{H}_{\mathrm{T}}\right)$ values, Equation (3) and then we predicted the advance rate of TBM according to the scheme proposed by Dietl \& Tarkoy (1970), (Tarkoy, 1973) where the last is a scheme represented the relationship between $\left(\mathrm{H}_{\mathrm{T}}\right)$ and advance rate of TBM based on statistical analysis for more than 95 rock samples that have correlation of coefficient about -0.85 (Fig.4).

$$
H_{T}=H_{R} \sqrt{H_{A}} \quad \text { (Tarkoy, 1973) }
$$

$\mathrm{H}_{\mathrm{T}}$ : Total hardness

$\mathrm{H}_{\mathrm{R}}$ : Schmidt rebound hardness

$\mathrm{H}_{\mathrm{A}}$ : Abrasion Hardness

Where $\mathrm{H}_{\mathrm{A}}=1 /(\mathrm{AB} / 100)$

\section{Results and Discussion}

Table 1 shows that the selected rock masses are not weathered or slightly weathered and the surfaces of the discontinuities (joints and bedding) are dry with some seepage and moisture in the rocks of sites 2 and 3 because of local ground water (Ruhi,1990). It is clear that the majority of the Pila Spi Formation rocks in this study are soft granules of chalky limestone (Jassim \& Goff 2006). There are two type of discontinuity in the study area represented by joints and bedding planes (Shakir et al., 2020) their spacing range from a few to very wide, with closed to medium aperture and have large to very large block size. As showing in the Table 2 that the values of the point load strength test $\left(\mathrm{I}_{\mathrm{s}}\right)$ are mostly high that can be classify the rocks in the study area into strong with a value of $6.1 \mathrm{MPa}$ and very strong with a value of $9.32 \mathrm{MPa}$, where the value of the $I_{s}$ affected by mineralogy, moisture content, texture and porosity (Hudson and Harrison , 1997; Bieniawski, 1975; Chau and Wong, 1996). The dry density values of the samples are close to each other with an average of $2.68 \mathrm{gm} / \mathrm{cm}^{3}$, which can be explained by the findings of (Othman et al., 2018). Table 3 shows that the values of Schmidt rebound hammer $\left(\mathrm{H}_{\mathrm{R}}\right)$ have highest value at the third site by 48.45 and lowest value at the first site by 44 generally shows high values because it depends on the surface smoothness, erosion, water content and mineral rock (Aydin and Basu, 2005). It is noted in the same table that the values of weight loss by the (Lose angles) $\left(\mathrm{H}_{\mathrm{A}}\right) \%$ do not exceed $22 \%$ and this is a clear indication of the hardness of the rocks under study. In order to achieve the aim of research and to predict the rate of advanced of TBM in the rocks of the study area, the total hardness $\left(\mathrm{H}_{\mathrm{T}}\right)$ values obtained from equation 3 were projecting on the chart proposed by Tarkoy (1973) and as shown in Fig. 4 that most of the values of total hardness correspond to the level of rate of advanced between $1.57-1.86 \mathrm{~m} / \mathrm{hr}$ and this confirms that the rock hardness is so high that the drilling machine is difficult to advance. The field data and the results obtained from the laboratory test all that supported the hardness of Pila Spi limestone which is close relationship with the rate of advancement of the TBM (Neaupane and Adhikari, 2006). 
Table 1. Field description of selected sites in the current study (New Zealand Geotechnical Society, 2005)

\begin{tabular}{|c|c|c|c|c|c|c|}
\hline Sample. & Lithology & Weathering & Seepage & Color & Grains & Discontinuity \\
\hline S1 & $\begin{array}{l}\text { Chalky } \\
\text { limestone }\end{array}$ & $\begin{array}{c}\text { Slightly } \\
\text { weathering }\end{array}$ & dry & $\begin{array}{c}\text { Yellowish } \\
\text { to white }\end{array}$ & fine & $\begin{array}{l}\text { Bedding and joints (moderately to } \\
\text { very wide space, moderately } \\
\text { aperture very large block size) }\end{array}$ \\
\hline S2 & $\begin{array}{l}\text { Chalky } \\
\text { limestone }\end{array}$ & $\begin{array}{c}\text { Slightly } \\
\text { weathering }\end{array}$ & $\begin{array}{c}\text { Dry to } \\
\text { evidence } \\
\text { water flow }\end{array}$ & yellowish & fine & $\begin{array}{l}\text { Bedding and joints (closed to very } \\
\text { widely space, moderately narrow } \\
\text { moderately wide aperture, very large } \\
\text { block size. }\end{array}$ \\
\hline S3 & Limestone & $\begin{array}{c}\text { Non } \\
\text { weathering }\end{array}$ & $\begin{array}{l}\text { Dry to } \\
\text { medium } \\
\text { seepage }\end{array}$ & Yellowish & fine & $\begin{array}{c}\text { Bedding and joints (closely to } \\
\text { widely space, closed aperture,large } \\
\text { block) }\end{array}$ \\
\hline S4 & $\begin{array}{l}\text { Chalky } \\
\text { limestone }\end{array}$ & $\begin{array}{c}\text { Slightly } \\
\text { weathering }\end{array}$ & dry & White & fine & $\begin{array}{c}\text { Bedding and joints (closely space, } \\
\text { narrow to moderate aperture, } \\
\text { medium block) }\end{array}$ \\
\hline S5 & $\begin{array}{l}\text { Chalky } \\
\text { limestone }\end{array}$ & $\begin{array}{c}\text { Slightly } \\
\text { weathering }\end{array}$ & dry & $\begin{array}{c}\text { Yellowish } \\
\text { to white }\end{array}$ & fine & $\begin{array}{l}\text { Bedding and joints (moderate to } \\
\text { wide space, moderately to wide } \\
\text { aperture, large block) }\end{array}$ \\
\hline
\end{tabular}

Table 2. Results of point load strength and dry density of samples

\begin{tabular}{cccc}
\hline Sample & Density $\left(\mathbf{g m} / \mathbf{c m}^{\mathbf{3}}\right)$ & Point load $\boldsymbol{I}_{\boldsymbol{s}(\mathbf{5 0})} \mathbf{M P a}$ & Rock strength classification (Anon,1977) \\
\hline S1 & 2.635 & 6.1 & strong \\
S2 & 2.692 & 8.51 & Very strong \\
S3 & 2.709 & 9.32 & Very strong \\
S4 & 2.687 & 9.08 & Very strong \\
S5 & 2.690 & 7.1 & Very strong \\
\hline
\end{tabular}

Table 3. Results of hardness by Schmidt hammer test $\left(H_{R}\right)$, abrasion $\%\left(H_{A}\right)$ and total hardness $\left(H_{T}\right)$

\begin{tabular}{|c|c|c|c|c|c|c|}
\hline \multirow[t]{2}{*}{ Sample } & \multirow{2}{*}{$\begin{array}{l}\text { Schmidt hammer } \\
\text { rebound average } \\
\text { value }\left(H_{R}\right)\end{array}$} & \multicolumn{2}{|c|}{ hardness by abrasion $H_{A}$} & \multirow[t]{2}{*}{ hardness } & \multirow{2}{*}{$\begin{array}{c}\text { Rate of } \\
\text { advance } \mathrm{m} / \mathrm{hr}\end{array}$} & \multirow{2}{*}{$\begin{array}{c}\text { Rate of advance } \\
\qquad \mathrm{ft} / \mathrm{hr}\end{array}$} \\
\hline & & $\begin{array}{c}\left(\boldsymbol{H}_{A}\right) \% \\
\text { Weight loss } \\
\text { in (gm) }\end{array}$ & $\begin{array}{l}\text { HA=1/Weight } \\
\text { loss in gm }\end{array}$ & & & \\
\hline $\mathrm{T} 1$ & 44 & 22 & 4.55 & 93.85 & 1.86 & 6.102 \\
\hline $\mathrm{T} 2$ & 45.71 & 20.96 & 5.06 & 102.2 & 1.75 & 5.74 \\
\hline $\mathrm{T} 3$ & 48.45 & 19.97 & 5.02 & 108.33 & 1.57 & 5.15 \\
\hline $\mathrm{T} 4$ & 48.1 & 21 & 4.76 & 104.94 & 1.64 & 5.38 \\
\hline $\mathrm{T} 5$ & 47 & 21.8 & 4.58 & 100.58 & 1.7 & 5.57 \\
\hline
\end{tabular}




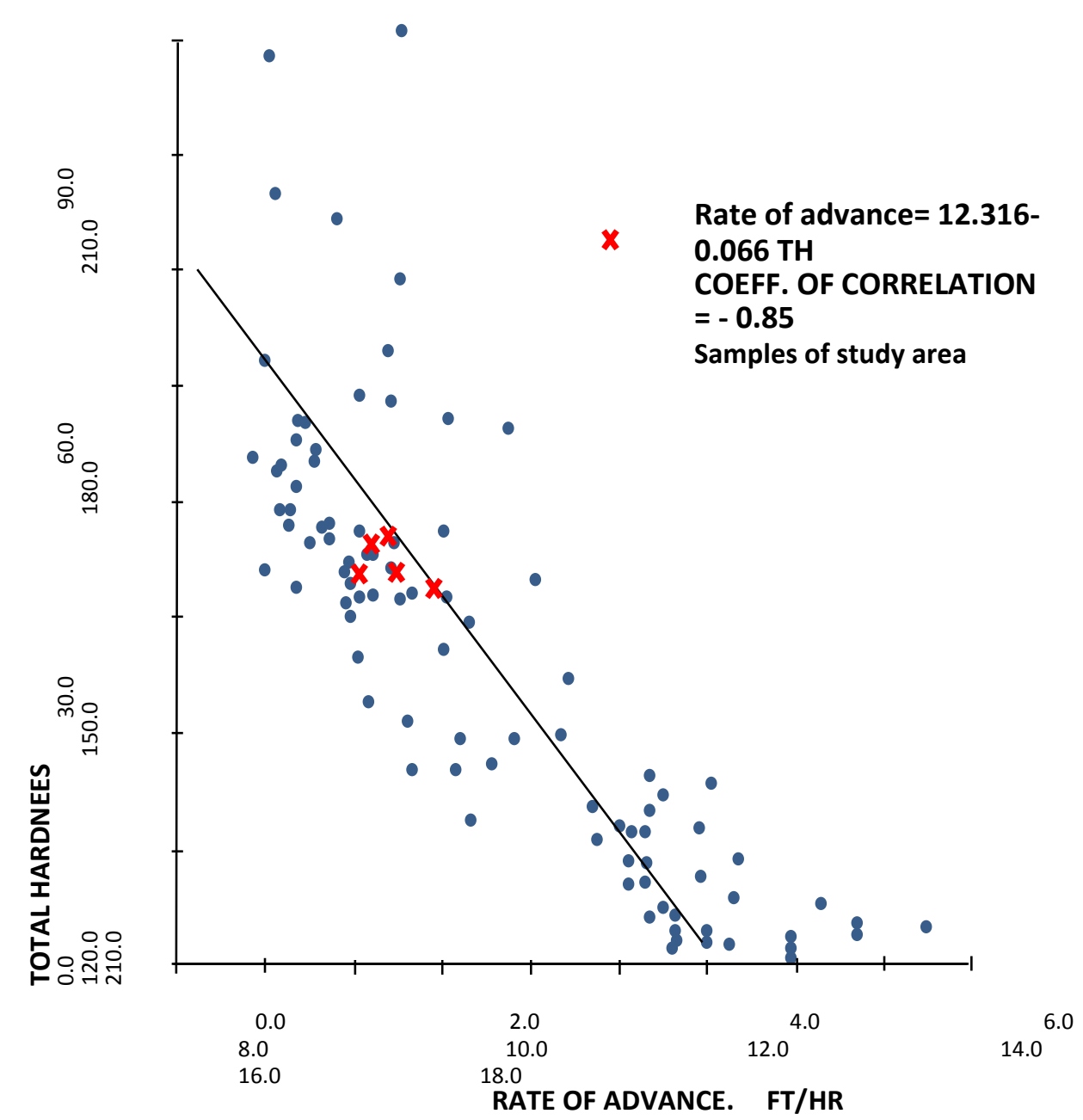

Fig. 4. Plot of data, showing statistical relation between total hardness and rate of advance (Tarkoy,1973) and 4 samples for study area

\section{Conclusions}

The rocks of the study area are classified as chalky limestone sometimes dolomitic rocks. These rocks are strong to very strong and fine-grained, with slightly weathered surfaces, relative humidity on some of the bedding planes and joints belonging to the Pila Spi Formation. This formation is located in the Qara Dagh anticline having an axis extended NW-SE northeast of Iraq. The results of the hardness tests represented by Schmidt hammer rebound value and Los Angeles indicate a high hardness of rocks consistent with field data. After dropping the total hardness values, we can conclude that there is a potential for the slow progress of the TBM tunneling machine if used in the rocks of the study area or any other area that have the same type of rock.

\section{Acknowledgments}

The authors are very grateful to the Editor in Chief Prof. Dr. Salih M. Awadh, the Secretary of Journal Mr. Samir R. Hijab. and the Technical Editors for their great efforts and valuable comments. 


\section{References}

Aydin, A. and Basu, A., 2005. The Schmidt hammer in rock material characterization. Engineering Geology, 81 (1), 1-14.

Bieniawski, Z. T., 1975. Point load test in geotechnical practice. Engineering Geology, (1), $1-11$.

Bieniawski, Z. T., S. and Galera, J. M., 2007. TBM excavability: prediction and machine-rock interaction. In: Proceedings, Rapid Excavation and Tunneling Conference, 1118-1130.

Broch, E., Franklin, J. A., 1972. The point load strength test. International Journal of Rock, Mechanics, Mining Sciences and. Geomechanical Abstracts, 9, 669-697.

Chau, K. T., and Wong, R. H. C., 1996. Uniaxial compressive strength and point load strength of rocks. International Journal Rock Mechanism, 33, 183-188.

Dhaher, K. A., 2009. Study of physical and geotechnical properties of some rock units of Pilaspi, Fatha and Injana formations in Shaqlawa area, northern Iraq, M. Sc., University of Baghdad.

Dietl, B., Tarkoy, P. J., 1973. A Study of Rock Hardness and Tunnel-Boring Machine Advance Rates in Manhattan Schist, Tunneling Technology Newsletter, Number 3, September 1973.s

Hansen, J., 2018. Comparison of existing performance prediction models for hard rock tunnel boring based on data collected at the Follo Line Project. NTNU Norwegian University of Science and Technology. M. Sc thesis, 60 PP.

Hassanpour, J., Rostami, J., Zaho, J., 2011. A new hard rock TBM performance prediction model for project planning. Tunnel Undergraduate Space Technology, 26, 595-603.

Howarth, D.F., Adamson, W.R., Berndt, J. R.,1986. Correlation of model tunnel boring and drilling machine performances with rock properties. International Journal of Rock Mechanism, 23 (2),171-175.

Hudson, J. A., Harrison, J. P., 1997. Engineering rock mechanics an introduction to the principles. elsevier science Ltd. The Boulevard, Langford Lane. Killington, Oxford OX5 IGB, UK.

Huggett, R. J., 2007. Fundamentals of Geomorphology. $2^{\text {nd }}$ edition. published in the Taylor \& Francis e-Library, 2007.

ISRM, 1978. International society of rock mechanics. Standardization of laboratory and field tests, commission on suggested methods for determining hardness and abrasiveness of rocks. International Journal Rock Mechanism, 15, 89-97.

ISRM, 1985. Suggested method for determining point load strength. International Journal of Rock Mechanics, Mining Sciences and Geomechanical Abstracts, 22, 51-60.

Jassim, S. Z., Goff, J. C., 2006. Geology of Iraq. $1^{\text {st }}$ edition. Dolin and Prague: Czech Republic.

Lee, S. W., Chang, S. H., Park, K. H., Kim, C. Y., 2011. TBM Performance and Development State in Korea. Procedia Engineering Volume 142011Pages 3170-3175.

Shakir, M., Barno, J., 2020. Rock joint analysis to determine the main stress field in Bustanah structure Northeast of Iraq. Iraqi Geological Journal, 53 (2C), 2020: 56-67.

Maleki, M. R., 2018. Rock Joint Rate (RJR); a new method for performance prediction of tunnel boring machines (TBMs) in hard rocks. Tunnelling and Underground Space Technology, 261-286.

Neaupane, K. M., Adhikari, N. R., 2006. Prediction of Tunneling-induced Ground Movement with the Multi-layer Perceptron, Tunneling and Underground Space Technology, 151-159.

New Zealand Geotechnical Society, 2005. Field description of soil and rock, New Zealand: Publication of NZ Geotechnical Society.

Omar, H. M., Ismail, N. R., 2015. The Suitability of Limestone from the Pilaspi Formation (Middle-Late Eocene) for Building Stone in Koya Area, NE Iraq. ARO, The Scientific Journal of Koya University 3 (2): DOI: 10.14500/aro.10068.

Othman, B. S., Ozcan, N. T, Kalender, A., Sonmez, H., 2018. Maltivariate Artificial Neural Networt (ANN) model for productive uniaxial compressive strength from index tests. EUROCK 2018, Geomechanics and Geodynamics rock mass, 1, Taylor and Francis Group.

Ruhi, J. F., 1990. Flow of ground of water through fractured carbonate rocks in the praire du chien-Jordan a quifer southeastern Minnesota U.S geological survey, department of the interior. 
Saffet, Y., Halil, K., 2015. Application of various optimization techniques and comparison of their performances for predicting TBM penetration rate in rock mass. International Journal of Rock Mechanics and Mining Sciences, 80, 308-315.

Saffet, Y., Rostami, J., Ozdemir L., 2008. Recommneded rock testing methods for predicting TBM performance: focus on the CSM and NTNU models. ISRM International Symposium 2008 th Asian Rock Mechanics Symposium (ARMS5), 24-26 November 2008 Tehran, Iran.

Saleh, D. G., 2012. The suitability of limestone of Fatha Formation for building and road aggregates in Nineveh governorate/ North Iraq, Journal of University of Anbar for Pure Science, 6(2),1-13.

Salimi, J., Rostami, C., Moormann, 2017. Evaluating the Suitability of Existing Rock Mass Classification Systems for TBM Performance Prediction by using a Regression Tree Procedia Engineering, 299-300.

Sissakian, V. K., Amin, R. M., Mohammed, J. G., 2018. Lateral growth of Qara Dagh anticline, south of Sulaimaniyah City, NE Iraq: a structural geomorphological study. Iraqi Bulletin of Geology and Mining, 14 (2), $31-47$.

Tarkoy, P. J., 1973. Predicting TBM penetration rates in selected rock types. Ninth Canadian Symposium on Rock Mechanics, Montreal, Canada, December, 13-15. 